\title{
A PARTICIPAÇÃO DOS SINDICATOS NA EXECUÇÃO DE POLÍTICAS PÚBLICAS E SUA INFLUÊNCIA NA REORGANIZAÇÃO DO ESPAÇO DAS EQUENAS CIDADES DO TERRITÓRIO DO SISAL (1990-2014)
}

\author{
André Silva de Jesus ${ }^{1}$ \& Edinusia Moreira Carneiro Santos ${ }^{2}$ \\ ${ }^{1}$ Bolsista PIBIC/FAPESB, Graduando em Geografia, Universidade Estadual de Feira de Santana e-mail: \\ andrecandeal@yahoo.com.br \\ ${ }^{2}$ Orientadora, Departamento de Ciências Humanas e Filosofia - DCHF, Universidade Estadual de Feira de Santana e-mail \\ nusiafs@hotmail.com
}

Palavras-Chave: Pequenas Cidade; Território do Sisal; Sindicatos.

\section{INTRODUÇÃO}

O presente trabalho resulta da execução parcial do Plano de Trabalho destina-se desenvolver atividades de pesquisa, voltada a analisar a atuação das organizações sindicais na execução de políticas públicas nas pequenas cidades de Candeal, Ichu, Lamarão, Barrocas, Teofilândia, Quijingue e Biritinga no Território do Sisal, bem como, a caracterização dessas políticas púbicas e seus desdobramentos na produção e (re)organização espacial da pequena cidade a partir dessa interação dialética campo-cidade e pontualmente enxergando os sindicatos na condição de agente de organização do espaço e na condição de mediador dessas relações.

\section{MATERIAIS E MÉTODOS OU METODOLOGIA}

O desenvolvimento das atividades de pesquisa propostas no plano de trabalho embora tenha sido executadas parcialmente, cumpriu duas fases, a saber.

A primeira fase, compreendeu a revisão de literatura e construção do referencial teórico-conceitual do recorte temático proposto, tendo em vista ampliar o acervo bibliográfico objetivando qualificar o desenvolvimento das atividades de pesquisa, esmiuçando o conceito e as diversas abordagens de espaço geográfico, organização espacial e pequena cidade, tentando a medida do possível uma abordagem conceitual e metodológica tendo as especificidades do Território do Sisal como ponto de partida.

A segunda fase, correspondeu ao levantamento e construção de base de dados sobre as organizações sindicais sediadas nas pequenas cidades, qualificando suas principais características, base social, focos de atuação, estrutura, etc,. Nesta fase, foi possível conseguir junto a Central Única dos Trabalhadores (CUT) apenas informações sobre a característica dos sindicatos baseados nas cidades foco da pesquisa.

\section{RESULTADOS E/OU DISCUSSÃO}

Podemos mencionar como principal resultado alcançado na construção do referencial teórico-conceitual, que contribuiu para o aprofundamento das discussões acumuladas nos 
semestres iniciais do curso. Para a construção do referencial teórico e das discussões sobre a conceituação de espaço e (re)organização espacial, pequena cidade e sindicato. Para a discussão do conceito de espaço, tomamos os seguintes autores como referência: Santos (1978); Moreira (1982); Correa (1990), para a discussão de pequena cidade, tomamos como referencias as discussões Spósito e Silva (2009), e por fim, as discussões sobre sindicato foram utilizados Mendonça (2009) e Santos e Silva (2010).

Foi possível concluir que a organização espacial como resultado das relações sociais de uma dada sociedade. Assim sendo, a sociedade em suas diferentes estruturas (jurídicas, cultural, ideológica, econômica, etc.,) expressam as regras formais ou informas pelas quais a própria sociedade, diga-se, em movimento dialético, materializará as maneiras de se organizar sobre o espaço.

Portanto, colocamos o espaço geográfico como o resultado de diferentes processos de relações sociais em condições determinadas, considerando que o próprio espaço não só é o reflexo das relações humanas, mas sobretudo condição para sua reprodução.

Dentro dessa discussão de (re)organização espacial, encontra-se as discussões sobre os diferentes agentes sociais e políticos que contribuem direta ou indiretamente para a (re)organização deste espaço cada agente é claro, agindo a partir de pontos de partida distintos, porém, envoltos nessa mesma ciranda dialética. Neste mesmo sentido, buscou-se compreender, dentro dessa conjuntura, a especificidade da pequena cidade dentro deste cenário particular da região sisaleira da Bahia que é resultante de um processo de construção territorial peculiar.

Vale mencionar, que, o processo de construção do referencial teórico foi momento imprescindível para a pavimentação de um caminho na execução de qualquer pesquisa acadêmica.

Além do referencial teórico, temos como resultado o levantamento das organizações sindicais com sede nos municípios alvo da pesquisa, os quais são Candeal, Ichu, Lamarão, Barrocas, Teofilândia, Quijingue e Biritinga. Foram identificadas as seguintes organizações sindicais com base nestes municípios: no município de Quijingue: Sindicato dos Trabalhadores Rurais e Agricultores Familiares de Quijingue - SINTRAFQ e Sindicato dos Servidores Públicos Municipais de Quijingue; no município de Ichu: Sindicato dos Trabalhadores Rurais e Agricultores Familiares de Ichu - SINTRAFI e Sindicato dos Servidores Públicos Municipais de Ichu; no município de Candeal: Sindicato dos Trabalhadores Rurais e Agricultores Familiares de Candeal - SINTRAFC e Sindicato dos Servidores Públicos Municipais de Candeal; no município de Lamarão: Sindicato dos Trabalhadores Rurais de Lamarão; no município de Biritinga: Sindicato dos Trabalhadores Rurais de Queimadas - STR e Sindicato dos Servidores Públicos Municipais de Biritinga; no município de Barrocas: Sindicato dos Trabalhadores Rurais e Agricultores Familiares de Barrocas - SINTRAFB; no município de Teofilândia: Sindicato dos Trabalhadores Rurais e Agricultores Familiares de Teofilândia SINFTRAFT. Todas essas organizações sindicais fazem parte da base da Central Única dos Trabalhadores em nível estadual e da central nacional que tem a mesma denominação.

\section{CONSIDERAÇÕES FINAIS}

Por tudo que foi visto, concluímos que a presente trabalho, resultante da execução parcial de bolsa de iniciação científica contribuiu decisivamente, para o aprimoramento dos 
conhecimentos acadêmicos, da mesma forma em que, contribuiu para o aprofundamento dos conhecimentos específicos sobre os temas tratados durante a pesquisa.

Do mesmo modo, a construção do referencial teórico-conceitual, a revisão bibliográfica e as atividades atinentes à bolsa, revelaram a riqueza da Ciência geográfica e suas múltiplas possibilidades de análise e compreensão dos processos que moldam nosso espaço, assim como, a maneira pela qual os agentes de produção deste espaço (Sindicatos, Associações, Estado, Empresas Privadas) atuam a partir da lógica intrínseca dos seus interesses ou visões para, nessa articulação dinâmica entre os agentes, ora de maneira contraditória, ora com intensões alinhadas, para (re)organizar o espaço da pequena cidade, desvelando as relações travadas sob aquele recorte do espaço.

Assim sendo, a relevância do estudo de agentes sociais, a exemplo dos Sindicatos, que, até então, não eram elevados a lugar de destaque nos estudos acadêmicos, especialmente na Geografia. A escolha do recorte temático, se deu principalmente em razão da proximidade com os movimentos sociais/sindical, e sobretudo, pela relevância que estas organizações tem na construção do espaço geográfico do Território do Sisal, e tem potencializado a espacialização de suas ações através da execução direta de políticas públicas originarias das esferas estadual e federal.

\section{REFERÊNCIAS BIBLIOGRÁFICAS E OUTRAS}

CORRÊA, Roberto Lobato. Região e Organização Espacial. $3^{a}$ ed. São Paulo: Ática, 1990.

ESPOSITO, Maria da Encarnação Beltrão. Para Pensar as Pequenas e Médias Cidades Brasileiras. Belém: FASE, ICSA - UFPA, 2009.

MENDONÇA, Patrícia Maria Emerenciano de. A profisssionalização do Campo no Desenvolvimento Rural na Região do Sisal. (Tese e Doutorado em Administração). São Paulo: Fundação Getúlio Vargas, 2009.

MOREIRA, Ruy. (Org). Geografia: Teoria e Crítica: o saber posto em questão. Petrópolis: Vozes, 1982.

SANTOS, E. M C. e SILVA, O. O da. Agentes Sociais de Produção do Espaço Rural no Território do Sisal - Bahia. Revista Campo-Território: revista de Geografia Agrária, v. 5, n. 9, p. 71-88., fev., 2010. 